\title{
Influence of Alkali Ions on Tribological Properties of Silicon Surface
}

\author{
Dariusz M. Jarzabek ${ }^{1}$ - Dorota Siewert ${ }^{2}$ - Wojciech Fabianowski ${ }^{3}$. \\ Helmut Schift ${ }^{2} \cdot$ Zygmunt Rymuza $^{3}$ - Thomas Jung ${ }^{2}$
}

Received: 1 December 2014/Accepted: 29 September 2015/Published online: 17 October 2015

(c) The Author(s) 2015. This article is published with open access at Springerlink.com

\begin{abstract}
Tribological properties of surfaces (friction, adhesion and wear) provide challenging limitations to the design of reliable machines on the micro- and nanometer scale as the surface to volume area increases and volume, mass and inertia of the mobile parts decrease. This study reports on the reduction in the friction force of silicon surfaces after the alkali metal ion exposure in the form of aqueous solutions. A scanning force microscope equipped with a liquid cell was used to investigate the friction force and the pull-off force of a flat silicon surface immersed in water and in different alkali metal chlorides solutions: $\mathrm{LiCl}, \mathrm{NaCl}$ and $\mathrm{CsCl}$. The concentration ranged from 0.1 up to $1000 \mu \mathrm{mol} / \mathrm{l}$. The changes in the free surface energy of the initial surface and of the modified surfaces after drying were determined from contact angle measurements and from the acid-base adhesion theory. In both cases, in the liquid environment and after drying of the exposed silicon substrates in air, the friction force is reduced by approximately $50 \%$. Our results provide new, fundamental insight into the exchange of surface termination layers in particular for tribology. Also it is suggested to use the procedure as a low-cost alternative to improve the tribological properties of the silicon surface in particular in
\end{abstract}

Electronic supplementary material The online version of this article (doi:10.1007/s11249-015-0603-5) contains supplementary material, which is available to authorized users.

Dariusz M. Jarzabek

djarz@ippt.pan.pl

1 Institute of Fundamental Technological Research, Polish Academy of Sciences, Pawinskiego 5B, 02-390 Warsaw, Poland

2 Paul Scherrer Institut, Villigen, Switzerland

3 Warsaw University of Technology, Warsaw, Poland applications where lubricating fluids are not appropriate, e.g., in nanomachines and devices.

Keywords Silicon surface - Scanning force microscopy · Friction · Adhesion · Alkali metal chlorides

\section{Introduction}

The silicon provides the most established and most commonly used material for micro-electro-mechanical systems (MEMS) due to well-established manufacturing processes capable of forming 3D structures by lithography and etching, but also due to its interesting mechanical and electric properties. Silicon benefits from very little fatigue and is almost perfectly Hookean material. The tribology of the silicon surface has also generated considerable recent research interest due to the fact that its tribological properties need to be improved and modified in order to ensure the reliability of micro-machines. With progressive miniaturization leading to decreasing size of the components, the relative contribution of contact forces and frictional forces to overall dissipative losses and to the kinetic energy of the mobile parts in operation decreases. Furthermore, these boundary conditions imply a different regime of tribology, specifically of rather low loads acting at interfaces. Therefore, solutions avoiding high-viscosity lubricants are sought after. Friction, adhesion and wear provide a significant challenge in the design of reliable MEMS and on these grounds. Nanotribology as a scientific discipline emerged, which comprises the investigation and control of tribological properties on the nanometer scale down to atoms and molecules [1-7]. Surface layers and surface ad-layers in general provide very interesting options here [8-13]. In the case of MEMS, it is particularly 
important to use surface layers or lubricants that are molecularly thick, easy applied, insensitive to environment and highly durable. Hence, one of the promising solutions is the ionic liquids [14-16]. On the other hand, numerous experiments have established that the water-lubricated ceramic interface provides a very low friction coefficient [17]. This effect has been also observed for the silicon surface [18]. Moreover, it was observed that ion implantation can significantly change the mechanical and tribological properties of the surface layer $[19,20]$. In the literature, it is also described that even single-atom-type replacement can significantly change the tribological properties of an interface [21-23]. Therefore, we established the idea of treatment of the silicon surface with simple alkali ions solutions in water. We assume that the presence of alkali ions in the silicon surface (because of the diffusion from the solution) can lead to creation of more stable water film due to electrostatic interactions.

In the present study, we investigate the effect of alkali metal salt solutions in water on the tribological properties of the silicon (100) surface. We use scanning force microscope (SFM) and complementary methods. Specifically, we report about a quantitative and time-dependent study of the surface chemical composition, the significant reduction in the friction force and the modified wetting behavior of flat silicon surfaces hours to days after their immersion in aqueous solutions of alkali metal chlorides.

\section{Experimental}

The current investigation involved friction force, pull-off force and surface energy measurements of flat silicon (100) n-type surfaces immersed in water and in three different salt solutions: lithium, sodium and cesium chlorides $(\mathrm{LiCl}$, $\mathrm{NaCl}$ and $\mathrm{CsCl}$ ). The concentration of the salt solutions ranged from 0.1 up to $1000 \mu \mathrm{mol} / \mathrm{l}$ in distilled water. Every $2 \mathrm{~h}$ the solution was changed to new and fresh one in order to assure the constant concentration of the ions. During the night the sample was put to the closed solution container. Therefore, the changes in the concentration should be insignificant. The experiments were performed with a Veeco Dimension 3100 SFM equipped with a liquid cell. Flat, n-type silicon (100) was used. Before the experiment, the surface was etched in a reactive ion etching (RIE) process, using equal quantities of $\mathrm{O}_{2}$ and $\mathrm{CHF}_{3}$ at $100 \mathrm{~m}$ Torr in a $100 \mathrm{~W}$ RF plasma. The oxide layer, which was created after the etching due to the contact of the sample with air, is about a few nanometers thick. Due to the RIE process, the silicon surface used in the experiments corresponds to the silicon surface in MEMS devices (they are usually etched by RIE). The applied normal force was equal to approximately $100 \mathrm{nN}$. This value was chosen due to the fact that it provides a good accuracy and resolution of the changes in the lateral force and still the wear was not observed. Firstly, measurements in the ambient environment were conducted. Later, the tip was immersed in the investigated liquid for $24 \mathrm{~h}$ in order to chemically equilibrate the tip's surface. SFM silicon cantilever with silicon tips from Micromasch was used. The diameter of the cantilever's tip varied between 100 and $200 \mathrm{~nm}$. The normal spring constants were determined from the resonant frequency and were usually equal to approximately $4 \mathrm{~N} / \mathrm{m}$. The sample was immersed in distilled water (this step was omitted when clean water was the liquid to be investigated). In order to investigate the time evolution of the friction force, SFM measurements were conducted in an open liquid cell for the first $8 \mathrm{~h}$ of immersion and then in the equilibrium state (after $24 \mathrm{~h}$ ). Each measurement was done at different places on the sample's surface. Hence, the influence of rubbing on the results was eliminated. Finally, the sample was dried in air and carefully cleaned with distilled water and isopropyl alcohol. The SFM tip was changed and the measurements were repeated in ambient environment.

In order to determine the friction force, so-called friction loops were acquired (Fig. 1a). The cantilever was moved across the sample in a $90^{\circ}$ angle with regard to the long cantilever axis in forward and then backward mode. The torsional flexure of the cantilever due to the frictional forces acting at the given force load was recorded and analyzed in the form of cyclic friction loops. The force measurements were calibrated by using the wedge calibration method, which is based on the earlier method developed by Ogletree et al. [24, 25]. It should be noted that the calibration is only valid for the setup used in the calibration experiment, i.e., for exactly this cantilever used in exactly this setup with the specific position of the laser spot of the beam deflection sensor. The values of the calibration constant were usually equal to approximately $10 \mathrm{nN} / \mathrm{mV}$. In order to measure the pull-off force to withdraw the cantilever tip from the surface, force-distance curves were recorded. These were obtained by slowly lowering the tip onto the sample surface until approach to contact and then further increasing the tip-to-surface load up to a preselected peak force before withdrawing the cantilever again. Figure $1 \mathrm{~b}$ shows an example of such a curve. Far away from the surface, there is no force acting on the cantilever. Close to the surface, the tip jumps into contact and then starts to deform or indent the sample. The pull-off force is then evaluated from the characteristic kink in the retracting curve which corresponds to the cantilever tip being released from the substrate.

Before the sample was immersed into the liquid for the first time and after the SFM experiments, as well as after drying/cleaning of the solution exposed surfaces, the 

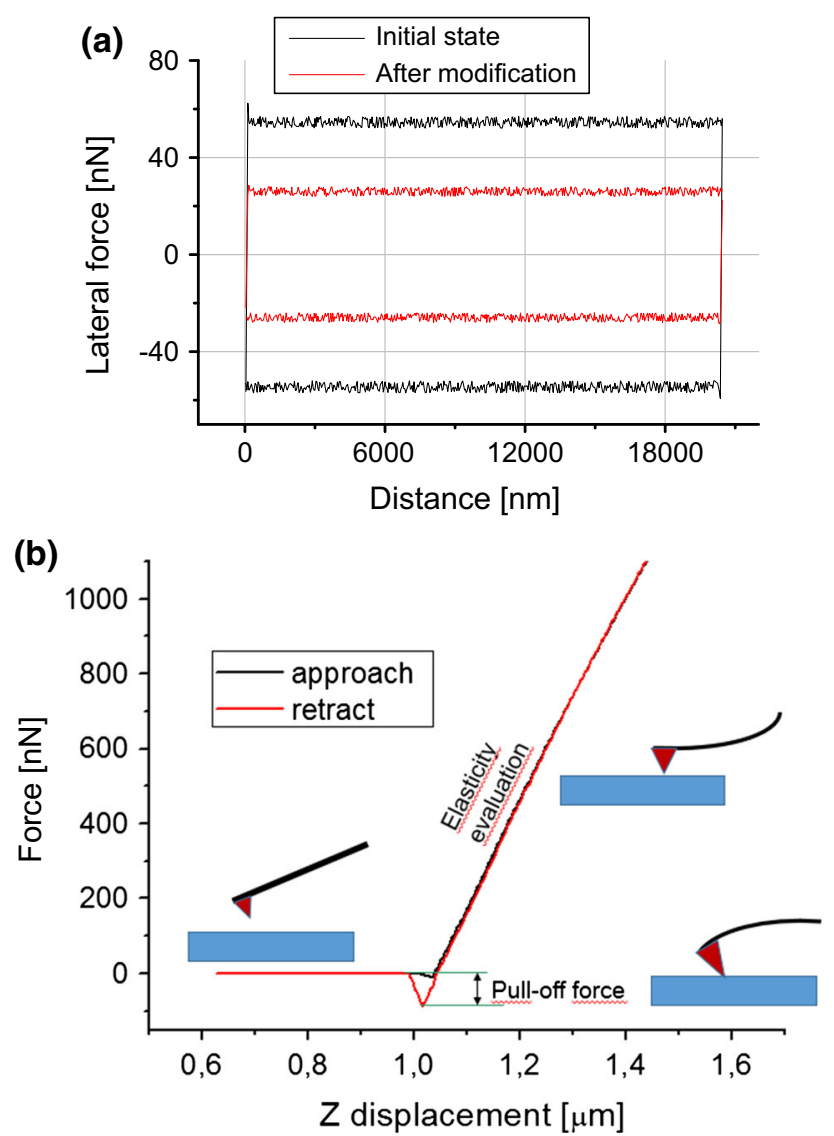

Fig. 1 AFM measurement techniques. a Friction loops-the wider friction loop corresponds to bigger friction force-initial state, the narrower loop corresponds to the state after the surface modification, b force-distance curves - they are obtained by slowly lowering the tip onto the sample surface, indentation of the surface and then slowly retracting the tip

surface free energy of the silicon surface was determined from contact angle measurements. According to the acidbase theory of adhesion, it is possible to evaluate the surface tension components for the surface under test and therefore the total surface energy using three different test liquids: [26].

$\gamma_{s}=\gamma_{s}^{d}+2\left(\gamma_{s}^{+} \gamma_{s}^{-}\right)^{\frac{1}{2}}=\gamma_{s}^{d}+\gamma_{s}^{A B}$

where $\gamma_{S}^{d}$ is the dispersive component of the overall surface free energy $\gamma_{S}, \gamma_{S}^{+}$and $\gamma_{S}^{-}$are acidic and basic components, respectively, and $\gamma_{S}^{A B}$ is the overall acid-base contribution to $\gamma_{s}$. In our measurements, we used three different liquids, of which the surface free energy components are well known: water, diiodomethane and glycerol. The components of the surface free energy of the investigated sample were then evaluated from the set of three equations. The measurements in air were done in a clean room, in which the temperature and humidity were controlled. The temperature was $22{ }^{\circ} \mathrm{C}$, and the relative humidity was equal to $55 \%$.
In order to confirm the presence of the alkali ions, the X-ray photoelectron spectroscopy (XPS) measurement was carried out on the samples immersed in $\mathrm{CsCl}$ solution and on those immersed in $\mathrm{H}_{2} \mathrm{O}$ for reference. XPS was performed in a vacuum chamber at a pressure of $\sim 5 \cdot 10 \mathrm{E}-11$ mbar with a monochromatized Al K-alpha radiation at a power of $400 \mathrm{~W}$. The presence of the elements is manifested by the appearance of the respective XPS peaks in a spectrum, i.e., at $\sim 723.7 \mathrm{eV}$ for Cs $3 \mathrm{~d}$ peak and $\sim 198.5 \mathrm{eV}$ for $\mathrm{Cl} 2 \mathrm{p}$ peak in alkali halides. Both peaks are split due to spin-orbit coupling, and the respective splitting is $13.9 \mathrm{eV}$ for $\mathrm{Cs}$ and $1.6 \mathrm{eV}$ for $\mathrm{Cl}$. All spectra have been shifted to match the binding energy of silicon at $99.3 \mathrm{eV}[27,28]$.

\section{Results}

\subsection{The Friction Force Reduction}

The friction force between the silicon SFM tip and the silicon surface modified by the influence of water and alkali chloride solutions was examined in a first series of the experiments. The data (Fig. 2) show that extended water exposure of the silicon surface reduces the friction force by about $40 \%$ on the timescale of about $5 \mathrm{~h}$. Note that an influence of the surface of the cantilever tip on this timescale can be ruled out because of its equilibration in water for a longer time period before the start of the experiment. A further reduction in the measured friction force occurs after immersion of the sample in salt solutions, i.e., for $\mathrm{CsCl}$ (Fig. 2a), $\mathrm{NaCl}$ and $\mathrm{LiCl}$ (Supplementary Information). In all three cases, the friction force was further reduced by about $70 \%$ with a characteristic half decay time of about $3 \mathrm{~h}$. It should be noted that across the range of the probed concentrations the reduction in the friction force is slightly dependent on the concentration of the solution. Note, however, that at the beginning of the exposure the decrease in the friction force is much faster for higher concentrations. The equilibrium is reached only after about $10 \mathrm{~h}$ for $0.1 \mu \mathrm{mol} / \mathrm{l}$ concentrations and already after about $2 \mathrm{~h}$ for $1000 \mu \mathrm{mol} / \mathrm{l}$ concentrations. On the contrary, the modification of the frictional force in water levels out after about $5 \mathrm{~h}$. Figure $2 \mathrm{a}$ shows the difference in the reduction in the friction force on samples exposed to three salt solutions of $10 \mu \mathrm{mol} / \mathrm{l}$ concentration. The friction force in $\mathrm{LiCl}$ solution is lower by approximately $25 \%$ than in $\mathrm{CsCl}$ solution. When the friction force was determined from measurements performed in different concentrations, the same trend was observed. It is important to note that the observed reduction in the friction force is persistent, also after removing the sample from the solution and drying. For example, the friction force between the silicon tip and 
Fig. 2 Results of the friction force measurement. Water reduces the friction force by about $40 \%$, and a further reduction is possible when the sample is immersed in alkali metal salt solution (a). The strongest reduction in the friction force was observed for lithium chloride, whereas the weakest for the cesium chloride (b)
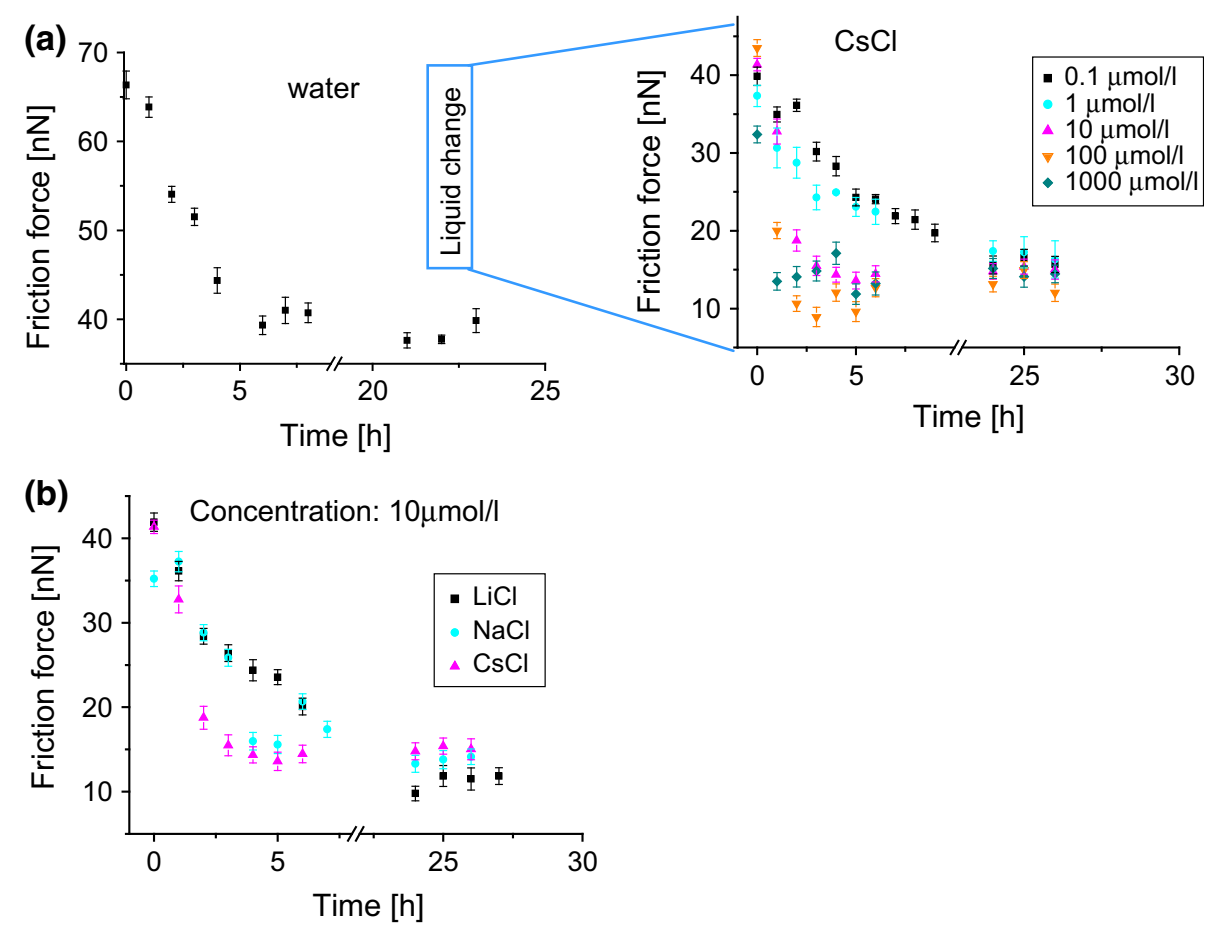

the silicon surface before immersion into the $10 \mu \mathrm{mol} / 1$ solutions was determined as $52 \pm 9 \mathrm{nN}$, whereas after the experiment, when the sample was dried and cleaned it assumed a value of $-28 \pm 4 \mathrm{nN}$ in the case of sodium and cesium chloride exposure and $24 \pm 4 \mathrm{nN}$ in the lithium chloride exposure case. It should be noted that the effect can be reversed by subsequent immersion in water. In this case, after $72 \mathrm{~h}$ of immersion and then drying and cleaning, the value of the friction force is back to its initial value.

\subsection{Adhesion, Free Surface Energy and XPS Results}

To complement our friction force measurements, the adhesion between the cantilever tip and the sample was measured. So-called pull-off force measurements were performed in salt solutions at concentrations of $1 \mathrm{mmol} / \mathrm{l}$. The results are shown in Fig. 3a. It is apparent that the value of the pull-off force is small and it is not altered by the applied salt solutions. Therefore, the change in the value of the adhesion force is not responsible for the changes in the friction force.

Our experiments provide consistent evidence that the ions modify the silicon surface on a rather long timescale of some hours or more. It is striking that also the free surface energy measurements performed after drying and cleaning the samples as they are shown in Fig. 3b confirm with this result (Table 1). The results indicate that the acidic part of the free surface energy and its overall value in all the cases increased about $30 \%$. Furthermore, XPS measurements (Fig. 4) indicate that samples before and after the modification show similar $\mathrm{Si}, \mathrm{O}$ and $\mathrm{C}$ peaks, in both binding energy position and intensity. $\mathrm{Cs}$ and $\mathrm{Cl}$ atoms are only present in the samples which were modified by the $\mathrm{CsCl}$ solutions, though their relative $1: 1(\mathrm{Cs}: \mathrm{Cl})$ stoichiometry is not conserved and amounts roughly to 9:1 (Supplementary Information). The chemical shift of the $\mathrm{Cs}_{3 / 2} \mathrm{~d}_{5 / 2}$ peak binding energy by $\sim 1 \mathrm{eV}$ with respect to the Cs metal $(\sim 726 \mathrm{eV})$ suggests a bond formation between Cs and oxygen $[27,28]$.

\section{Discussion}

As outlined in the introduction, prior work has documented the effectiveness of self-assembled monolayers to improve the tribological properties of a silicon surface. It was also observed that water reduces the friction force of this surface. In this paper, we tested the alkali chlorides and their influence on these properties and we have discovered that permanent reduction in the friction force may be achieved consequent to the immersion of the silicon sample in one of the following salts solutions in water: $\mathrm{LiCl}, \mathrm{NaCl}$ or $\mathrm{CsCl}$. Furthermore, we have investigated the time evolution of the changes in the friction force due to the SFM measurements in the liquid cell. It is apparent that by the interaction between the silicon surface and the ions contained in the solutions, a new surface layer is created.

In order to explain the chemistry of this layer the silicon surface, it should be noted that silicon is known to spontaneously form thin layers of oxide on its surface under 
Fig. 3 Results of the pull-off force (a) and surface energy (b) evaluation. The changes in the pull-off force are negligible. The acidic part of the free surface energy and its overall value in all alkali metal chlorides solutions has increased by approximately $30 \%$
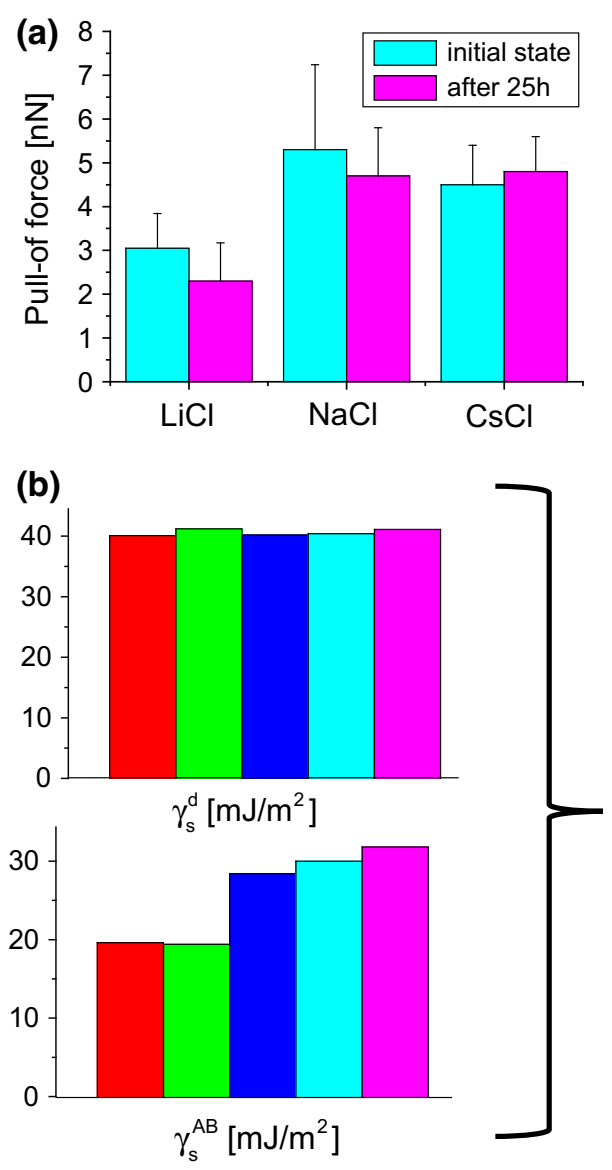

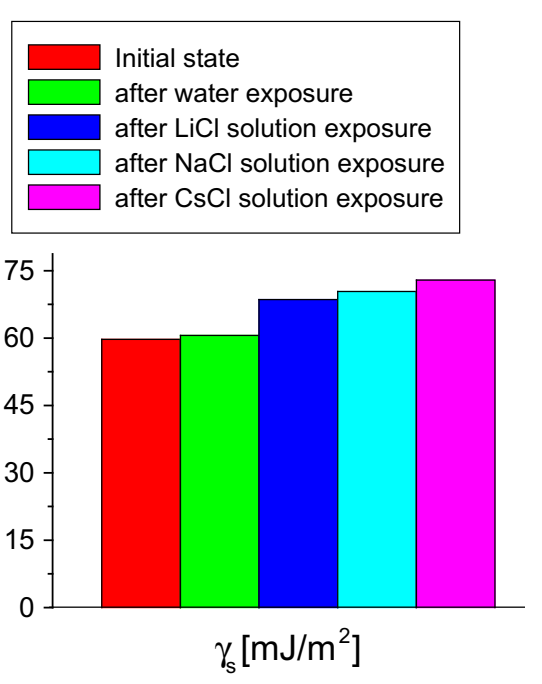

Table 1 Reduction in the friction force due to the salt influence

\begin{tabular}{lll}
\hline Friction force $(\mathrm{nN})$ & & \\
\hline Initial state & After surface modification & \\
\hline $52 \pm 8$ & $\mathrm{LiCl}$ & $24 \pm 4$ \\
& $\mathrm{NaCl}$ & $28 \pm 4$ \\
& $\mathrm{CsCl}$ & $28 \pm 4$ \\
\hline
\end{tabular}

normal atmospheric conditions. The microstructure of the interface is not clearly understood [29]. It is well known, however, that the interface between silicon and its ultrathin native oxide layer contains a high concentration of defects in the form of silicon dangling bonds (approximately $0.1 \mathrm{~nm}^{-1}$; Fig. 4a) [30]. Therefore, the oxide layer via these dangling bonds can react with water and form silanol groups on the surface (Fig. 4b) [31]:

$\mathrm{Si}-\mathrm{O}-\mathrm{Si}+\mathrm{H}_{2} \mathrm{O} \rightleftarrows 2 \mathrm{SiOH}$

This process may reduce the friction force and is in line with an earlier experimental report [18]. Our results show a further reduction in the friction force by exposure of the silicon surface to the $\mathrm{LiCl}, \mathrm{NaCl}$ or $\mathrm{CsCl}$ solutions in water. We attribute this effect to the replacement of hydrogen ions at the interface with alkali ions, as depicted (Fig. 4c). At room temperature, the silicon surface is electrically neutral at $\mathrm{pH} 2$ [32]. The lithium, sodium and cesium chloride solutions exhibit a $\mathrm{pH}$ of approximately 6,7 and 8, respectively [32]. At higher $\mathrm{pH}$, the concentration of $\equiv \mathrm{Si}-$ $\mathrm{O}^{-}$groups is higher and the hydrogen atom replacement reaction should occur faster. This assumption agrees with our results in that the observed reduction in the friction force occurs fastest for cesium chloride solutions and slowest for lithium chloride solutions (Fig. 2b). It is also possible that $\mathrm{Cs}$ ions have a higher sticking coefficient on the silicon surface and are absorbed more rapidly. Due to the fact that the alkali ions are bigger than the hydrogen ions, it is plausible that they introduce a higher internal stress to the thin oxide layer of silicon dioxide which may reduce the contact area and influence the friction force. Furthermore, the presence of the alkali ions is responsible for the creation of the more stable water film on the silicon surface due to the electrostatic interactions between water particles and the ions (Fig. 4c). The water film lubricates then the contact between the surface and the SFM tip and reduces friction. The presence of the alkali ions on the surface was further confirmed by the XPS (insets in Fig. 4). The fact that the effect can be reversed by subsequent immersion in water also suggests that the ions diffusion is 
Fig. 4 Model of the chemical modification of the ultrathin oxide layer on the silicon surface and the XPS results. a The silicon dangling bonds (red) which are created in the oxide layer. b Silanol groups created in water-free silanol (red), geminal silanols (blue) and associated silanols (green). c The replacement of the hydrogen atoms by alkali atoms (blue) and creation of the stable water thin film. XPS results confirm that $\mathrm{Cs}$ and $\mathrm{Cl}$ atoms are only present in the samples which were modified by the salt solutions, though their relative $1: 1(\mathrm{Cs}: \mathrm{Cl})$ stoichiometry is not conserved and amounts roughly to $9: 1$ (Color figure online) (a)

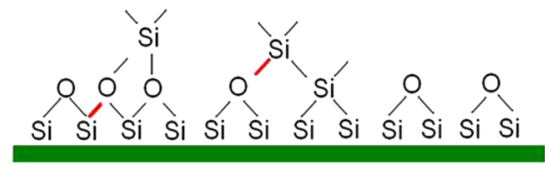

(b)

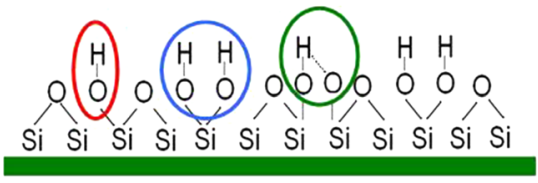

(c)

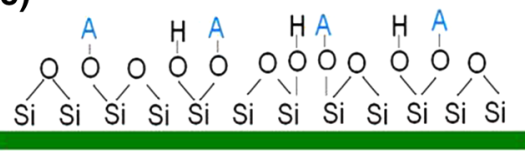

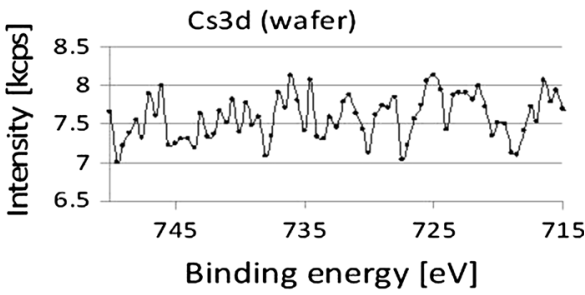
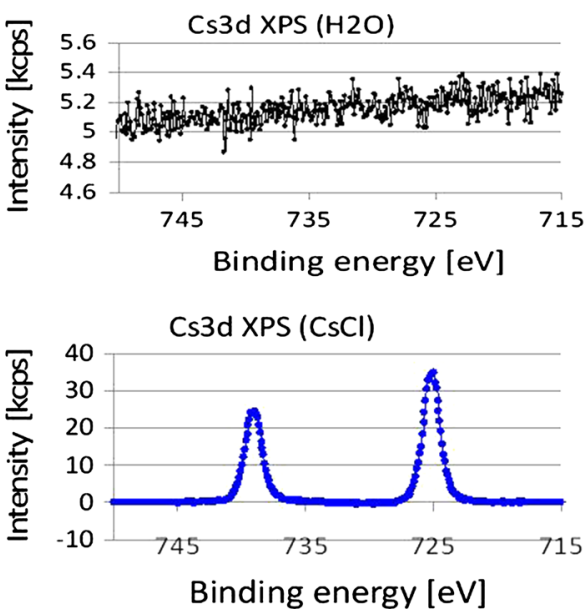

the explanation of the reduction in the friction force. The distilled water may leach the ions and after drying the silicon surface is back to its initial state.

The changes in the free surface energy (Fig. 3b) provide independent support toward this model: The silanol groups are not well hydrated with water; therefore, they are not stable in air, and water evaporates from the silicon surface; hence, water does not persistently change the free surface energy after drying. On the other hand, alkali ions may permanently bond to the thin oxide layer and influence its free surface energy and wettability. Furthermore, alkali ions are Lewis acids, which explains the increase in only the acidic part of the free surface energy. The strongest effect was observed for cesium chloride solutions. There are two complementary explanations. Firstly, the cesium chloride solutions exhibit the highest $\mathrm{pH}$ at the same concentrations, thereby the highest concentration of the $\equiv \mathrm{Si}-$ $\mathrm{O}^{-}$groups, where ion bonds are created. On the other hand, the cesium ions have the lowest potential to diffuse deeper into the silicon oxide. Hence, most of the Cs ions remain on the surface, bond water and contribute to the observed stronger increase in the acidic part of the free surface energy in comparison with the smaller ions which can diffuse easier. However, to fully explain this effect further research is needed. Evidently, the simple model presented here cannot describe all details of the experimentally observed, persistent and significant reduction in the friction force after exposure of $\mathrm{Si}$ to salt solutions.

It should be noted that the chlorides may cause the corrosion of MEMS devices. However, the above- described effect is caused by the alkali ions. Hence, it is possible to modify the surface by other, less aggressive salts, i.e., nitrates. On the other hand, the salt solutions can simulate biological environments in which in the near future MEMS and NEMS (nanoelectromechanical systems) can and should work [33, 34]. The effect of friction force reduction may be very useful for design of such devices. Unfortunately, using MEMS in aqueous environment has some challenges (i.e., viscosity, electrolysis and anodization [35]). Therefore, the effect of friction reduction should be further investigated in order to find out the optimal parameters.

\section{Conclusions}

To the best knowledge of the authors, the data that show the reduction in friction force due to the influence of the alkali ions on the silicon surface are the first of its kind. Our experiments provide the compelling evidence that the friction force can be reduced by approximately $50 \%$ by immersion in low-concentration alkali metal chlorides solutions in water. We tentatively attribute this effect to the bonding between alkali ions and the silicon surface. The ions contribute to the creation of the more stable water film, which lubricates the contact. These promising results are encouraging and should be explored in different configurations (e.g., by using different ionic compounds and in a wider concentration range). Other tribological properties such as wear on the nanometer and macroscale should also 
be investigated. This could eventually lead to methods for the low-cost modification of the surface friction coefficients and to new, strong, durable and affordable microand nanomachines made of silicon. Furthermore, it may be useful in the technological processes in which the friction force of a silicon surface plays an essential role, i.e., in the nanoimprint lithography.

Acknowledgments This work was done within the framework the Scientific Exchange Programme (SCIEX, project no. 10.021) between the Paul Scherrer Institut and the Warsaw Technical University. The authors would like to thank R. Schelldorfer, C. Spreu, V. Guzenko, A. Lücke and A. Weber for their help and technical assistance. This work has been also partially supported by the European Union in the framework of European Social Fund through the Warsaw University of Technology Development Programme.

Open Access This article is distributed under the terms of the Creative Commons Attribution 4.0 International License (http://crea tivecommons.org/licenses/by/4.0/), which permits unrestricted use, distribution, and reproduction in any medium, provided you give appropriate credit to the original author(s) and the source, provide a link to the Creative Commons license, and indicate if changes were made.

\section{References}

1. de Boer, M.P., Mayer, T.M.: Tribology of MEMS. Mrs Bull. 26(4), 302-304 (2001). doi:10.1557/mrs2001.65

2. Jarzabek, D.M., Rymuza, Z., Horiba, A., Hirai, Y.: Development of an experimental technique for testing rheological properties of ultrathin polymer films used in nanoimprint lithography. J. Vac. Sci. Technol. B (2011). doi:10.1116/1.3656377

3. Stempfle, P., Bourrat, X., Rousseau, M., Lopez, E., Takadoum, J.: Nanotribology of nacre: anisotropic dissipation in a multiscale hybrid material. Tribol. Int. 63, 250-264 (2013). doi:10.1016/j. triboint.2012.09.010

4. Zimmermann, F.M., Shan, J.W.: Rotational friction of single-wall carbon nanotubes in liquid suspension. Appl. Phys. Lett. 94, 053107 (2009). doi:10.1063/1.3033365

5. Ghaednia, H., Babaei, H., Jackson, R.L., Bozack, M.J., Khodadadi, J.M.: The effect of nanoparticles on thin film elasto-hydrodynamic lubrication. Appl. Phys. Lett. 103(26), 263111 (2013). doi:10.1063/1.4858485

6. Jarzabek, D.M., Kaufmann, A.N., Schift, H., Rymuza, Z., Jung, T.A.: Elastic modulus and fracture strength evaluation on the nanoscale by scanning force microscope experiments. Nanotechnology 25(21), 215701 (2014). doi:10.1088/0957-4484/25/ 21/215701

7. Stelmachowski, J.M., Rymuza, Z., Eisenmenger-Sittner, C.: Surface properties of $\mathrm{AlCuFeB}$ coatings with focus on resolving tribological issues of nanoimprint lithography. RSC Adv. 4(56), 29474-29478 (2014). doi:10.1039/c4ra01888e

8. Burkinshaw, M., Neville, A., Morina, A., Sutton, M.: The lubrication of both aluminium-silicon and model silicon surfaces with calcium sulphonate and an organic antiwear additive. Tribol. Int. 67, 211-216 (2013). doi:10.1016/j.triboint.2013.07.006

9. Jarzabek, D., Rymuza, Z., Wada, T., Ohmae, N.: Mechanical and tribological behaviour of carbon nanotube brushes. Int. J. Mater. Res. 99(8), 883-887 (2008). doi:10.3139/146.101716
10. Jarzabek, D., Rymuza, Z., Ohmae, N.: Friction and adhesion of carbon nanotube brushes. Int. J. Mater. Res. 100(7), 973-977 (2009). doi:10.3139/146.110140

11. Milligan, J., Shockley, J.M., Chromik, R.R., Brochu, M.: Tribological performance of Al-12Si coatings created via electrospark deposition and spark plasma sintering. Tribol. Int. 66, 1-11 (2013). doi:10.1016/j.triboint.2013.04.006

12. Stempfle, P., Besnard, A., Martin, N., Domatti, A., Takadoum, J.: Accurate control of friction with nanosculptured thin coatings: application to gripping in microscale assembly. Tribol. Int. 59, 67-78 (2013). doi:10.1016/j.triboint.2012.05.026

13. Klyatskina, E., Espinosa-Fernandez, L., Darut, G., Segovia, F., Salvador, M.D., Montavon, G., et al.: Sliding wear behavior of $\mathrm{Al} 2 \mathrm{O} 3-\mathrm{TiO} 2$ coatings fabricated by the suspension plasma spraying technique. Tribol. Lett. 59(1), 8 (2015). doi:10.1007/ s11249-015-0530-5

14. Bhushan, B., Palacio, M., Kinzig, B.: AFM-based nanotribological and electrical characterization of ultrathin wear-resistant ionic liquid films. J. Colloid Interface Sci. 317(1), 275-287 (2008). doi:10.1016/j.jcis.2007.09.046

15. Palacio, M., Bhushan, B.: Ultrathin wear-resistant ionic liquid films for novel MEMS/NEMS applications. Adv. Mater. 20(6), 1194 (2008). doi:10.1002/adma.200702006

16. Nainaparampil, J.J., Eapen, K.C., Sanders, J.H., Voevodin, A.A.: Ionic-liquid lubrication of sliding MEMS contacts: comparison of AFM liquid cell and device-level tests. J. Microelectromech. Syst. 16(4), 836-843 (2007). doi:10.1109/JMEMS.2007.901628

17. Tomizawa, H., Fischer, T.E.: Friction and wear of silicon-nitride and silicon-carbide in water-hydrodynamic lubrication at low sliding speed obtained by tribochemical wear. Asle Trans. 30(1), 41-46 (1987)

18. Kim, D.I., Kim, K.H., Ahn, H.S.: Tribological properties of adsorbed water layer on silicon surfaces. Int. J. Precis. Eng. Manuf. 11, 741-746 (2010)

19. Takeda, K., Mitsui, K., Tobushi, H., Levintant-Zayonts, N., Kucharski, S.: Influence of nitrogen ion implantation on deformation and fatigue properties of TiNi shape memory alloy wire. Arch. Mech. 65(5), 391-405 (2013). doi:10.1007/s12541-0100087-z

20. Swiatek, Z., Michalec, M., Levintant-Zayonts, N., Bonarski, J., Budziak, A., Bonchyk, O., et al.: Structural evolution of nearsurface layers in NiTi alloy caused by an ion implantation. Acta Phys. Pol. A 120(1), 75-78 (2011)

21. Zhang, Y.N., Hanke, F., Bortolani, V., Persson, M., Wu, R.Q.: Why sliding friction of $\mathrm{Ne}$ and $\mathrm{Kr}$ monolayers is so different on the $\mathrm{Pb}(111)$ surface. Phys. Rev. Lett. 106(23), 4 (2011). doi:10. 1103/PhysRevLett.106.236103

22. Krim, J.: Friction and energy dissipation mechanisms in adsorbed molecules and molecularly thin films. Adv. Phys. 61(3), 155-323 (2012). doi:10.1080/00018732.2012.706401

23. Huang, Q., Yu, D.L., Xu, B., Hu, W.T., Ma, Y.M., Wang, Y.B., et al.: Nanotwinned diamond with unprecedented hardness and stability. Nature 510(7504), 250 (2014). doi:10.1038/nature13381

24. Ogletree, D.F., Carpick, R.W., Salmeron, M.: Calibration of frictional forces in atomic force microscopy. Rev. Sci. Instrum. 67(9), 3298-3306 (1996). doi:10.1063/1.1147411

25. Varenberg, M., Etsion, I., Halperin, G.: An improved wedge calibration method for lateral force in atomic force microscopy. Rev. Sci. Instrum. 74(7), 3362-3367 (2003). doi:10.1063/1.1584082

26. Fowkes, F.M.: Attractive forces at interfaces. Ind. Eng. Chem. 56(12), 40 (1964)

27. Moulder, J.F.: Handbook of X-ray Photoelectron Spectroscopy. Perkin-Elmer Corp, Eden Praire (1992)

28. Hwang, C.C., An, K.S., Park, R.J., Kim, J.S., Lee, J.B., Park, C.Y., et al.: Cesium core level binding energy shifts at the O-2/ 
Cs/Si(113) surface. J. Electron Spectrosc. Relat. Phenom. 88, 733-739 (1998). doi:10.1016/S0368-2048(97)00278-8

29. Munkholm, A., Brennan, S., Comin, F., Ortega, L.: Observation of a distributed epitaxial oxide in thermally grown $\mathrm{SiO}_{2}$ on $\mathrm{Si}$ (001). Phys. Rev. Lett. 75(23), 4254-4257 (1995). doi:10.1103/ PhysRevLett.75.4254

30. Dabrowski, J., Casali, R.A., Mussig, H.J., Baierle, R., Caldas, M.J., Zavodinsky, V.: Mechanism of dopant segregation to $\mathrm{SiO}_{2} /$ Si(001) interfaces. J. Vac. Sci. Technol. B 18(4), 2160-2164 (2000). doi:10.1116/1.1306310

31. Cole, D.J., Payne, M.C., Ciacchi, L.C.: Water structuring and collagen adsorption at hydrophilic and hydrophobic silicon surfaces. Phys. Chem. Chem. Phys. 11(48), 11395-11399 (2009). doi:10.1039/b816125a
32. Sjoberg, S.: Silica in aqueous environments. J. Non-Cryst. Solids 196, 51-57 (1996). doi:10.1016/0022-3093(95)00562-5

33. Feng, J., Cho, S.K.: Mini and micro propulsion for medical swimmers. Micromachines 5(1), 97-113 (2014). doi:10.3390/ $\operatorname{mi} 5010097$

34. Zhang, Y.A., Tao, J.Y., Wang, Y.L., Ren, Z.Q., Liu, B., Chen, X.: The effect of water on the mechanical properties of native oxide coated silicon structure in MEMS. Microelectron. Reliab. 53(9-11), 1672-1675 (2013). doi:10.1016/j.microrel.2013.07.018

35. Sounart, T.L., Michalske, T.A., Zavadil, K.R.: Frequency-dependent electrostatic actuation in microfluidic MEMS. J. Microelectromech. Syst. 14(1), 125-133 (2005). doi:10.1109/JMEMES. 2004.839006 